\title{
Association of Fine Particulate Matter Exposure with Acute Noncardiovascular Critical IIlnesses and In-hospital Outcomes in Patients Receiving Intensive Cardiac Care
}

\section{Fei Chen}

Sichuan University West China Hospital

Qi Liu

Sichuan University West China Hospital

\section{Baotao Huang}

Sichuan University West China Hospital

\section{Fangyang Huang}

Sichuan University West China Hospital

\section{Yiming Li}

Sichuan University West China Hospital

\section{Yong Peng ( $\sim$ pengymd@126.com )}

Sichuan University West China Hospital https://orcid.org/0000-0001-9562-4622

\section{Mao Chen}

Sichuan University West China Hospital

\section{Research article}

Keywords: Fine particulate matter, Acute noncardiovascular critical illness, Acute cardiac care, Prognosis

Posted Date: March 13th, 2020

DOI: https://doi.org/10.21203/rs.2.20005/v2

License: (9) This work is licensed under a Creative Commons Attribution 4.0 International License. Read Full License

Version of Record: A version of this preprint was published at BMC Public Health on May 1st, 2020. See the published version at https://doi.org/10.1186/s12889-020-08758-7. 


\section{Abstract}

Background The effect of short-term exposure to fine particulate matter (PM2.5) on the incidence of acute noncardiovascular critical illnesses (ANCls) and clinical outcomes is unknown in patients with acute cardiovascular diseases.

Methods We conducted a retrospective study in 2,337 admissions to an intensive cardiac care unit (ICCU) from June 2016 to May 2017. We used the 2-day average PM2.5 concentration before ICCU admission to estimate the individual exposure level, and patients were divided into 3 groups according to the concentration tertiles. Major ANCl was defined as the composite of acute respiratory failure, acute kidney injury, gastrointestinal hemorrhage, or sepsis. The primary endpoint was all-cause death or discharge against medical advice in extremely critical condition.

Results During the 12-month study period, the annual median concentration of PM2.5 in Chengdu, China was $48 \mu \mathrm{g} / \mathrm{m} 3$ (IQR, 33-77 $\mu \mathrm{g} / \mathrm{m} 3$ ). More than 20 percent of admissions were complicated by major ANCl, and the primary endpoints occurred in $7.6 \%$ of patients during their hospitalization. The association of short-term PM2.5 exposure levels with the incidence of acute respiratory failure (adjusted OR [odds ratio] $=1.31,95 \% \mathrm{Cl}$ [confidence interval]1.12-1.54) and acute kidney injury (adjusted OR=1.20,95\% Cl 1.02-1.41) showed a significant trend. Additionally, there were numerically more cases of sepsis (adjusted $\mathrm{OR}=1.21$, $95 \% \mathrm{Cl} 0.92-1.60$ ) and gastrointestinal hemorrhage (adjusted $\mathrm{OR}=1.29,95 \% \mathrm{Cl} 0.94-1.77$ ) in patients with higher exposure levels. After further multivariable adjustment, short-term PM2.5 exposure levels were still significantly associated with incident major $\mathrm{ANCl}$ (adjusted $\mathrm{OR}=1.32,95 \% \mathrm{Cl} 1.12-1.56$ ), as well as a higher incidence of the primary endpoint (adjusted OR=1.52, 95\% $\mathrm{Cl} 1.09-2.12$ ).

Conclusion Short-term PM2.5 exposure before ICCU admission was associated with an increased risk of incident major $\mathrm{ANCl}$ and worse in-hospital outcomes in patients receiving intensive cardiac care.

\section{Introduction}

During the past two decades, the body of evidence regarding the hazardous effect of ambient air pollution on public health has grown substantially $(1,2)$. The Global Burden of Disease (GBD) Study 2016 showed that ambient particulate matter had become the sixth-leading risk factor for disability-adjusted life-years globally, and $11.1 \%$ of all death could be attributed to it in China (3). Among various particulate matters, fine particulate matter, of which the aerodynamic diameter is less than $2.5 \mu \mathrm{m}\left(\mathrm{PM}_{2.5}\right)$, is widely considered as the predominant pollutant (3-5). Moreover, many observational studies have found that the risk of acute cardiovascular events and mortality was significantly associated with short-term $\mathrm{PM}_{2.5}$ exposure in the general population (6-8).

In recent years, researchers also noted that acute noncardiovascular critical illnesses (ANCI) were prevalent and correlated with increased mortality in patients with acute cardiovascular diseases admitted to intensive cardiac care units (ICCUs), who tended to be elderly and complicated by numerous chronic comorbidities $(9,10)$. Theoretically, the effect of short-term $\mathrm{PM}_{2.5}$ exposure on these susceptible patients 
who need intensive cardiac care is unlikely to be limited to the cardiovascular system (2), hence it is interesting whether short-term $\mathrm{PM}_{2.5}$ exposure is correlated with the risk of incident $\mathrm{ANCl}$ in these patients. However, no studies to date have been conducted to explore such a correlation.

We tested the hypothesis that short-term exposure to ambient fine particulate matter is associated with an increased risk of incident major ANCl and worse clinical outcomes in ICCU patients.

\section{Methods}

\section{Study Population}

We studied consecutive admissions to the ICCU at West China Hospital affiliated to Sichuan University, an academic tertiary care center located in Chengdu, China, from June 2016 to May 2017. In our hospital, patients with cardiovascular diseases who require acute cardiac care but do not require unscheduled surgery or postsurgical management, are admitted to the ICCU. All the admissions to our ICCU during the study period were eligible for screen $(n=2,873)$. We excluded admissions of patients without cardiovascular diseases $(n=6)$, patients with an ICCU stay lasting less than 4 hours after scheduled interventional procedures $(n=150)$, and admissions of patients who were younger than 16 years old $(n=139)$. If a patient was ever admitted to the ICCU more than once during the same hospital stay, his/her admissions not meeting the exclusion criteria mentioned above were combined into one (296 into 143). Further, we removed the non-first admissions for patients with multiple ICCU admissions during the study period $(n=88)$.

We systematically queried the electronic medical records and carefully reviewed all available information to obtain demographics, vital signs, laboratory data, cardiovascular and noncardiovascular diagnoses, therapeutic interventions, length of stay (LOS), and clinical outcomes. The type of admission was categorized as medical if no relevant interventional procedure was performed in the 7 days before or after ICCU admission. The local institutional review board approved this study, with a waiver of informed consent.

\section{Environmental Data}

We obtained daily $\mathrm{PM}_{2.5}$ data from the China National Environmental Monitoring Centre (http://www.cnemc.cn/) and China Air Quality Online Monitoring and Analysis Platform (https://www.aqistudy.cn). $\mathrm{PM}_{2.5}$ concentrations were measured using methods based on technical specifications issued by the Ministry of Environmental Protection in state-controlled monitoring sites. The 24-hour mean $\mathrm{PM}_{2.5}$ concentration was simply averaged from all valid sites in this city. We used the average of 24-hour mean $\mathrm{PM}_{2.5}$ concentration of the preceding day and the current day of ICCU admission to estimate the individual short-term exposure level. To adjust the impact of weather conditions, we obtained daily mean temperature and relative humidity from the National Meteorological Information Center (http://data.cma.cn/). 


\section{Complexity and Severity of Illnesses}

To assess the complexity of chronic illnesses of each ICCU admission, we calculated the Charlson Comorbidity Index (CCl), which is a weighted index that takes into account the number and the seriousness of comorbid disease (11). Meanwhile, we also adopted the Oxford Acute Severity of Illness Score (OASIS) to evaluate acute severity of illnesses. OASIS includes 10 variables that can be easily captured, such as vital signs and mechanical ventilation status, and the final OASIS is the sum of the worst score of all the components across the first 24 hours after ICCU admission (12).

\section{Key Variable Definitions}

The composite of acute respiratory failure, acute kidney injury, gastrointestinal hemorrhage, or sepsis was defined as major $\mathrm{ANCl}$, based on their prevalence and odds ratios for mortality reported by previous ICCU studies $(9,10)$. The primary endpoint was the composite of all-cause death or discharge against medical advice (DAMA) in extremely critical condition, defined as the composite of circulatory shock, electrical instability requiring emergency medical interventions, or acute respiratory failure with the need for mechanical ventilation. The DAMA in extremely critical condition of critically ill patients is a relatively common phenomenon in China for a variety of reasons, including specific traditional prohibitions, financial concerns, and the lack of social support, etc., and those patients often suffer death shortly. Compared with all-cause death, the composite primary endpoint may reflect clinical outcomes of the study population more accurately.

\section{Statistical Analysis}

Based on the tertiles of the 2-day average concentration of $\mathrm{PM}_{2.5}$ before ICCU admission, patients were divided into low-exposure $\left(\leq 36 \mu \mathrm{g} / \mathrm{m}^{3}\right)$, medium-exposure $\left(37-63 \mu \mathrm{g} / \mathrm{m}^{3}\right)$, and high-exposure $\left(\geq 64 \mu \mathrm{g} / \mathrm{m}^{3}\right)$ groups. Baseline characteristics, major therapeutic interventions, and clinical outcomes were compared among patient groups. For continuous variables, we calculated means \pm standard deviation or median (interquartile range, IQR), and the differences were tested using One-way Analysis of Variance or KruskalWallis Tests, respectively. For categorical variables, we calculated counts and percentages, and Linear-byLinear Association Chi-Square Tests were used to assess tendency changes across patient groups. To detect odds ratios for important characteristics according to short-term $\mathrm{PM}_{2.5}$ exposure levels in study population, we utilized Multivariate Binary Logistic Regression Models, controlling for mean temperature (per $5^{\circ} \mathrm{C}$ increase) and relative humidity (per 10\% increase). To explore the predictors of the incidence of the primary endpoint, we developed a Multivariate Binary Logistic Regression Model, adjusting for the 2day average concentration of $\mathrm{PM}_{2.5}$ and weather conditions before ICCU admission, demographics, complexity and severity of illnesses, cardiogenic shock, ventricular arrhythmia, and major ANCI. A twosided $P$ value of less than 0.05 was considered as statistically significant. We performed all the statistical analyses in SPSS software (version 24.0).

\section{Results}


A total of 2,337 ICCU admissions were included in this study. The mean age of the patients was $65.6 \pm 14.2$ years, and male patients accounted for $68.0 \%$. Most patients were admitted via emergency department (68.6\%), and approximately 80 percent $(77.8 \%)$ of patients underwent interventional procedures, in particular, nearly one-third (31.5\%) of patients underwent unscheduled procedures.

During the 12-month study period, the annual median concentration of $\mathrm{PM}_{2.5}$ in Chengdu, China was 48 $\mu \mathrm{g} / \mathrm{m}^{3}$ (IQR, 33-77 $\mu \mathrm{g} / \mathrm{m}^{3}$ ), which was much higher than the theoretical minimum risk exposure level (2.4$5.9 \mu \mathrm{g} / \mathrm{m}^{3}$ ) defined by the GBD Study 2016 (3). The concentration was also significantly higher than the levels $\left(13.8-27.7 \mu \mathrm{g} / \mathrm{m}^{3}\right.$ ) reported by epidemiological studies conducted in some developed countries (13, 14).

The baseline characteristics of the patients stratified by the 2-day average $\mathrm{PM}_{2.5}$ exposure levels before ICCU admission are presented in Table 1. There were differences in the source or type of admission, acute coronary syndrome (ACS), incident cardiac arrest, the rate of major ANCl, and acute severity of illnesses among patient groups. Even after controlling for weather conditions, the correlation of short-term $\mathrm{PM}_{2.5}$ exposure with admission via emergency department (aOR [adjusted odds ratio] $=1.24,95 \% \mathrm{Cl}$ [confidence interval] 1.10-1.40), admission for ST-segment elevation myocardial infarction (STEMI) (aOR=1.23, 95\% Cl 1.09-1.39), undergoing unscheduled procedures ( $a O R=1.30,95 \% C / 1.15-1.46)$, and the incidence of acute respiratory failure $(a O R=1.31,95 \% C l 1.12-1.54)$ or acute kidney injury ( $a O R=1.20,95 \% C l 1.02-1.41)$, showed a significant trend with increasing exposure levels (Figure 1, panel A and B). Additionally, there were numerically more cases of cardiac arrest ( $a O R=1.21,95 \% C l 0.98-1.51)$, sepsis $(a O R=1.21,95 \% C l$ $0.92-1.60)$, and gastrointestinal hemorrhage $(a O R=1.29,95 \% C / 0.94-1.77)$ in patients with higher $\mathrm{PM}_{2.5}$ exposure (Figure 1, panel A and B). After further adjusting for age, $\mathrm{CCl}$, cardiogenic shock, ventricular arrhythmia, and weather conditions, the incidence of major ANCI was still significantly correlated with short-term $\mathrm{PM}_{2.5}$ exposure levels ( $a O R=1.32,95 \%$ Cl 1.12-1.56).

Major therapeutic characteristics of the patients are shown in Table 2. Consistent with the increasing trend of major $\mathrm{ANCl}$, patients with higher $\mathrm{PM}_{2.5}$ exposure were more likely to receive invasive hemodynamic monitoring, such as arterial line $(a O R=1.22,95 \% C / 1.05-1.41)$ and central venous catheter $(a O R=1.24,95 \% C l 1.02-1.49)$, as well as mechanical ventilation ( $a O R=1.34,95 \% C l 1.13-1.58)$ and hemodialysis $(a O R=1.52,95 \% C / 1.04-2.21)$ after considering weather conditions (Figure 1, panel C).

Median LOS in ICCU and hospital were 1.1 days (IQR, 0.8-2.6 days) and 6.3 days (IQR, 3.8-10.9 days), respectively. The overall rate of primary endpoint was $7.6 \%$ during hospitalization of study patients, with $6.5 \%$ occurring in ICCU. Clinical outcomes were considerably different among patient groups (Table 3 ). In accordance with the larger proportion of greater OASIS and more major ANCI in patients with higher $\mathrm{PM}_{2.5}$ exposure, primary endpoint ( $\left.a O R=1.46,95 \% \mathrm{Cl} 1.18-1.82\right)$, as well as that occurring in ICCU $(a O R=1.44,95 \% C / 1.14-1.82)$, were more frequent in these patients after controlling for weather conditions (Figure 1, panel D). 
The association between multiple predictors and in-hospital outcomes is displayed in Figure 2. After further multivariable adjustment, short-term $\mathrm{PM}_{2.5}$ exposure levels before ICCU admission were still strongly associated with a higher incidence of the primary endpoint ( $a O R=1.52,95 \% \mathrm{Cl} 1.09-2.12$, $P=0.015)$. However, the correlation between short-term $\mathrm{PM}_{2.5}$ exposure levels and primary endpoints occurring in ICCU was no longer statistically significant after the adjustment $(a O R=1.44,95 \% C / 0.98-2.13$, $P=0.067)$, possibly because of less statistical power due to fewer events occurring in ICCU.

\section{Discussion}

In an academic tertiary care center, we investigated 2,337 patients admitted to the ICCU over the course of one year, and found that short-term $\mathrm{PM}_{2.5}$ exposure before ICCU admission was associated with an increased risk of incident major ANCI (especially acute respiratory failure and acute kidney injury), greater acute severity of illnesses, increased need for advanced monitoring and therapeutic devices, as well as worse clinical outcomes. To our knowledge, this is the first study to report the short-term effect of ambient air pollution on patients who need acute cardiac care.

A large number of time-series studies have demonstrated that short-term $\mathrm{PM}_{2.5}$ exposure was associated with increased risk for near-term myocardial infarction, cardiac arrest, and mortality in the general population, although there was heterogeneity in the effect estimates in different studies (6-8). Our data were mostly in agreement with previous studies. We also found that the increased risk of STEMI seemed to be more pronounced than that of other types of ACS, though admission bias could not be excluded as a contributing factor. Possible biological mechanisms contributing to the acute cardiovascular effect of $\mathrm{PM}_{2.5}$ exposure have been well described. Three broad intermediary pathways, including systemic oxidative stress and inflammation, autonomic imbalance favoring sympathetic activation, and potential direct actions of particulate matters reaching the systemic circulation, as well as the subsequent specific biological responses (e.g., endothelial dysfunction, vasoconstriction, plaque vulnerability, decreased heart rate variability, etc.), have been proposed to underlie cardiovascular events following short-term $\mathrm{PM}_{2.5}$ exposure $(15,16)$. These underlying mechanisms may be primarily responsible for the difference in cardiovascular events in vulnerable ICCU patients exposed to variant $\mathrm{PM}_{2.5}$ levels.

We also found that the incidence of major $\mathrm{ANCl}$ was more prevalent in ICCU patients with higher shortterm $\mathrm{PM}_{2.5}$ exposure. Thus far, studies about the health effect of ambient fine particulate matter have focused on the general population, while there have been no investigations of this effect in individuals requiring acute cardiac care. Due to the aging population and increasing chronic comorbidities, the vulnerability of these susceptible individuals tends to be more significant than that of the general population (17). Consequently, these patients may suffer a larger clinically meaningful impact of shortterm $\mathrm{PM}_{2.5}$ exposure that is not limited to the cardiovascular system. On the other hand, some studies have reported that $\mathrm{ANCl}$ is common and associates with increased mortality risk in contemporary ICCU settings $(9,10)$. In consideration of a possible multisystemic consequence following short-term $\mathrm{PM}_{2.5}$ 
exposure and the meaningfulness of $\mathrm{ANCl}$, it is crucial to explore whether short-term $\mathrm{PM}_{2.5}$ exposure is associated with the incidence of major ANCl. Our findings confirm the existence of this association.

Previous studies have linked short-term $\mathrm{PM}_{2.5}$ exposure to the increased risk of decreased lung function $(18,19)$ and acute respiratory failure $(20,21)$ in apparently healthy individuals. The mechanism suggested to explain this acute health effect is the acute airway response caused by activation of inflammatory pathways and small airway constriction owing to the chemical constituents of inhaled fine particulates $(18,21)$. For vulnerable ICCU patients, the poorer physiological and pulmonary reserve could result in a more pronounced decrease in lung function following short-term $\mathrm{PM}_{2.5}$ exposure. This in turn may increase the risk of incident acute respiratory failure. Furthermore, some studies found that one-year $\mathrm{PM}_{2.5}$ exposure was associated with lower renal function in the general population $(22,23)$. Although no human studies have ever investigated whether short-term PM2.5 exposure is linked to the incidence of acute kidney injury, some animal experiments have demonstrated that short-term exposure to fine particulates, urban particulates, or diesel exhaust particulates, could induce inflammation and oxidative stress in peri-renal adipose tissue (24), increase cytokine expression in the kidney (25), and aggravate experimental acute renal failure (26) in rats, respectively. We speculated that there might be certain biomechanisms linking short-term $\mathrm{PM}_{2.5}$ exposure to the increased risk of acute kidney injury because of the marked vulnerability and high $\mathrm{PM}_{2.5}$ exposure of our study population, but further investigations are needed.

Numerous prior studies found that short-term elevated $\mathrm{PM}_{2.5}$ was associated with the risk of infections, especially acute respiratory infection $(27,28)$. However, the only study that investigated the association of $\mathrm{PM}_{2.5}$ exposure with incident community-acquired sepsis, did not yield statistically significant results (29). The cause for the increase in the number of sepsis cases in higher $\mathrm{PM}_{2.5}$ exposure groups in our study population may be iatrogenic and may be attributed to catheter-related or ventilation-related infections resulting from the more use of advanced hemodynamic monitoring and therapeutic devices due to the more significant acute severity of illnesses. Similarly, studies examining the correlation between short-term $\mathrm{PM}_{2.5}$ exposure and gastrointestinal hemorrhage have also failed to yield positive results $(30,31)$. However, though one study reported a positive correlation between elevation in nitric oxide and an increased risk of gastrointestinal hemorrhage, the researchers admitted that distinguishing between the individual effects of nitric oxide and $\mathrm{PM}_{2.5}$ was challenging because they were highly correlated (30). Hence, the causes for numerically more episodes of gastrointestinal hemorrhage in patients with higher $\mathrm{PM}_{2.5}$ exposure in our study may represent either an effect of nitric oxide or PM2.5. A greater number of stress ulcers related to the increased acute severity of illnesses may also be a contributing factor.

In brief, short-term $\mathrm{PM}_{2.5}$ exposure may increase the incidence of $\mathrm{ANCl}$, a major risk factor for mortality in ICCU patients (10), and this may be mediated via some biological mechanisms in addition to its cardiovascular effect. On this basis, the complex physiological interactions between the organs or physiological systems (e.g., cardiopulmonary interaction, cardiorenal interaction, etc.) secondary to ANCl 
and acute cardiovascular diseases may further exacerbate the acute severity of illnesses, increase the need for advanced hemodynamic monitoring and therapeutic devices, and worsen clinical outcomes. Furthermore, the increase in emergency room visits for cardiopulmonary diseases caused by severe air pollution (32) may delay the time of first medical contact and increase the risk of mortality in patients with higher short-term $\mathrm{PM}_{2.5}$ exposure. All of the above may provide an explanation for the association between short-term $\mathrm{PM}_{2.5}$ exposure and the increased need for advanced devices and worse clinical outcomes in our study.

Our study should be interpreted in the context of the following limitations. First, $\mathrm{PM}_{2.5}$ exposure measurement errors were inevitable because we simply averaged monitoring results across various sites as the proxy for actual individual exposure. However, this is an inherent disadvantage of all human studies involving air pollution. Second, despite the calculation of the $\mathrm{PM}_{2.5}$ levels in the period of 2 days, the time of patient's exposure to the external environment was not known. Third, potential confounders from other pollutants could not be entirely excluded because they usually correlate highly with $\mathrm{PM}_{2.5}$ concentration, although we found no similar association in the preliminary analysis. Forth, the interaction between ambient air pollution and weather conditions was intricate, as in previous studies, the adjustment for meteorological variables in our regression models may not exclude unmeasured cofounders. Fifth, the relatively small sample size made it impossible for us to perform further analyses to find whether some subgroup patients were more susceptible to short-term $\mathrm{PM}_{2.5}$ exposure. Finally, samples in this single-center study were subject to geographical restrictions, which affected their representativeness and generalization. Further high-quality multicenter time-series studies are needed to provide more evidence regarding this issue.

\section{Conclusion}

Short-term $\mathrm{PM}_{2.5}$ exposure before ICCU admission was associated with an increased risk of incident major acute noncardiovascular critical illnesses and worse in-hospital outcomes in patients receiving intensive cardiac care.

\section{Abbreviations}

GBD, the Global Burden of Disease Study; $\mathrm{PM}_{2.5}$, fine particulate matter; ANCl, acute noncardiovascular critical illness; ICCU, intensive cardiac care unit; LOS, length of stay; $\mathrm{CCl}$, Charlson Comorbidity Index; OASIS, Oxford Acute Severity of IIIness Score; DAMA, discharge against medical advice; IQR, interquartile range; aOR, adjusted odds ratio; STEMI, ST-segment elevation myocardial infarction.

\section{Declarations}

Ethics approval and consent to participate 
The study protocol was approved by the institutional review boards of West China Hospital, Sichuan University, with a waiver of informed consent.

\section{Consent for publication}

Not applicable

\section{Availability of data and material}

The datasets used and/or analyzed during the current study are available from the corresponding author on reasonable request.

\section{Competing interests}

The authors declare that they have no competing interests.

\section{Funding}

The present study received grants from the National High-tech Research and Development Program of China (Grant number: 2012AA02A510, Beijing, China), and Chinese National Nature Science Foundation (Grant numbers: 81370219 and 81400267, Beijing, China).

\section{Authors' contributions}

FC and QL designed the study, collected the data, and drafted the article. BTH analysed the data and revised the article. FYH and YML collected the data and revised the article. YP and MC designed the study, drafted the article and revised it. All the co-authors finally contributed to the final approval of the version to be published. All authors read and approved the final manuscript.

\section{Acknowledgements}

Not applicable.

\section{Reference}

1. Brunekreef B, Holgate ST. Air pollution and health. Lancet (London, England). 2002;360(9341):123342.

2. Kelly FJ, Fussell JC. Air pollution and public health: emerging hazards and improved understanding of risk. Environmental geochemistry and health. 2015;37(4):631-49.

3. Gakidou E, Afshin A, Abajobir AA, Abate KH, Abbafati C, Abbas KM, et al. Global, regional, and national comparative risk assessment of 84 behavioural, environmental and occupational, and metabolic risks or clusters of risks, 1990-2016: a systematic analysis for the Global Burden of Disease Study 2016. The Lancet. 2017;390(10100):1345-422. 
4. Chen R, Yin P, Meng X, Liu C, Wang L, Xu X, et al. Fine Particulate Air Pollution and Daily Mortality. A Nationwide Analysis in 272 Chinese Cities. Am J Respir Crit Care Med. 2017;196(1):73-81.

5. Zanobetti A, Schwartz J. The effect of fine and coarse particulate air pollution on mortality: a national analysis. Environ Health Perspect. 2009;117(6):898-903.

6. Mustafic H, Jabre P, Caussin C, Murad MH, Escolano S, Tafflet M, et al. Main air pollutants and myocardial infarction: a systematic review and meta-analysis. Jama. 2012;307(7):713-21.

7. Teng TH, Williams TA, Bremner A, Tohira H, Franklin P, Tonkin A, et al. A systematic review of air pollution and incidence of out-of-hospital cardiac arrest. Journal of epidemiology and community health. 2014;68(1):37-43.

8. Atkinson RW, Kang S, Anderson HR, Mills IC, Walton HA. Epidemiological time series studies of PM2.5 and daily mortality and hospital admissions: a systematic review and meta-analysis. Thorax. 2014;69(7):660-5.

9. Sinha SS, Sjoding MW, Sukul D, Prescott HC, Iwashyna TJ, Gurm HS, et al. Changes in Primary Noncardiac Diagnoses Over Time Among Elderly Cardiac Intensive Care Unit Patients in the United States. Circ Cardiovasc Qual Outcomes. 2017;10(8):e003616.

10. Holland EM, Moss TJ. Acute Noncardiovascular Illness in the Cardiac Intensive Care Unit. J Am Coll Cardiol. 2017;69(16):1999-2007.

11. Charlson ME, Pompei P, Ales KL, MacKenzie CR. A new method of classifying prognostic comorbidity in longitudinal studies: development and validation. Journal of chronic diseases. 1987;40(5):373-83.

12. Johnson AE, Kramer AA, Clifford GD. A new severity of illness scale using a subset of Acute Physiology And Chronic Health Evaluation data elements shows comparable predictive accuracy. Critical care medicine. 2013;41(7):1711-8.

13. Samoli E, Stafoggia M, Rodopoulou S, Ostro B, Declercq C, Alessandrini E, et al. Associations between fine and coarse particles and mortality in Mediterranean cities: results from the MEDPARTICLES project. Environ Health Perspect. 2013;121(8):932-8.

14. Dai L, Zanobetti A, Koutrakis P, Schwartz JD. Associations of fine particulate matter species with mortality in the United States: a multicity time-series analysis. Environ Health Perspect. 2014;122(8):837-42.

15. Brook RD, Rajagopalan S, Pope CA, 3rd, Brook JR, Bhatnagar A, Diez-Roux AV, et al. Particulate matter air pollution and cardiovascular disease: An update to the scientific statement from the American Heart Association. Circulation. 2010;121(21):2331-78.

16. Claeys MJ, Rajagopalan S, Nawrot TS, Brook RD. Climate and environmental triggers of acute myocardial infarction. European heart journal. 2017;38(13):955-60.

17. Dudzinski DM, Januzzi JL, Jr. The Evolving Medical Complexity of the Modern Cardiac Intensive Care Unit. Journal of the American College of Cardiology. 2017;69(16):2008-10.

18. Rice MB, Ljungman PL, Wilker EH, Gold DR, Schwartz JD, Koutrakis P, et al. Short-term exposure to air pollution and lung function in the Framingham Heart Study. Am J Respir Crit Care Med. 2013;188(11):1351-7. 
19. Lee JT, Son JY, Cho YS. The adverse effects of fine particle air pollution on respiratory function in the elderly. Sci Total Environ. 2007;385(1-3):28-36.

20. Guaita R, Pichiule M, Mate T, Linares C, Diaz J. Short-term impact of particulate matter $(P M(2.5))$ on respiratory mortality in Madrid. International journal of environmental health research. 2011;21(4):260-74.

21. Lin H, Tao J, Kan H, Qian Z, Chen A, Du Y, et al. Ambient particulate matter air pollution associated with acute respiratory distress syndrome in Guangzhou, China. Journal of exposure science \& environmental epidemiology. 2018;28(4):392-9.

22. Chen SY, Chu DC, Lee JH, Yang YR, Chan CC. Traffic-related air pollution associated with chronic kidney disease among elderly residents in Taipei City. Environmental pollution (Barking, Essex : 1987). 2018;234:838-45.

23. Mehta AJ, Zanobetti A, Bind MA, Kloog I, Koutrakis P, Sparrow D, et al. Long-Term Exposure to Ambient Fine Particulate Matter and Renal Function in Older Men: The Veterans Administration Normative Aging Study. Environ Health Perspect. 2016;124(9):1353-60.

24. Sun L, Liu C, Xu X, Ying Z, Maiseyeu A, Wang A, et al. Ambient fine particulate matter and ozone exposures induce inflammation in epicardial and perirenal adipose tissues in rats fed a high fructose diet. Particle and fibre toxicology. 2013;10:43.

25. Thomson EM, Vladisavljevic D, Mohottalage S, Kumarathasan P, Vincent R. Mapping acute systemic effects of inhaled particulate matter and ozone: multiorgan gene expression and glucocorticoid activity. Toxicological sciences : an official journal of the Society of Toxicology. 2013;135(1):169-81.

26. Nemmar A, Al-Salam S, Zia S, Yasin J, Al Husseni I, Ali BH. Diesel exhaust particles in the lung aggravate experimental acute renal failure. Toxicological sciences : an official journal of the Society of Toxicology. 2010;113(1):267-77.

27. Nhung NTT, Schindler C, Dien TM, Probst-Hensch N, Perez L, Kunzli N. Acute effects of ambient air pollution on lower respiratory infections in Hanoi children: An eight-year time series study. Environ Int. 2018;110:139-48.

28. Horne BD, Joy EA, Hofmann MG, Gesteland PH, Cannon JB, Lefler JS, et al. Short-term Elevation of Fine Particulate Matter Air Pollution and Acute Lower Respiratory Infection. Am J Respir Crit Care Med. 2018.

29. Sarmiento EJ, Moore JX, McClure LA, Griffin R, Al-Hamdan MZ, Wang HE. Fine Particulate Matter Pollution and Risk of Community-Acquired Sepsis. International journal of environmental research and public health. 2018;15(4).

30. Tian L, Qiu H, Sun S, Tsang H, Chan KP, Leung WK. Association between emergency admission for peptic ulcer bleeding and air pollution: a case-crossover analysis in Hong Kong's elderly population. The Lancet Planetary health. 2017;1(2):e74-e81.

31. Quan S, Yang H, Tanyingoh D, Villeneuve PJ, Stieb DM, Johnson M, et al. Upper gastrointestinal bleeding due to peptic ulcer disease is not associated with air pollution: a case-crossover study. BMC gastroenterology. 2015;15:131. 
32. Abrams JY, Weber RJ, Klein M, Samat SE, Chang HH, Strickland MJ, et al. Associations between Ambient Fine Particulate Oxidative Potential and Cardiorespiratory Emergency Department Visits. Environ Health Perspect. 2017;125(10):107008.

\section{Tables}

Table 1. Baseline characteristics of ICCU admission 


\section{Characteristic}

Age, yrs

Age $\geq 65$ yrs

Male, n (\%)

Source of admission, $\mathrm{n}(\%)$ Department of Emergency General Ward of Cardiology Other Departments

Type of admission, $\mathrm{n}$ (\%)

Medical

Scheduled procedure

Unscheduled procedure

Vital signs

Temperature, ${ }^{\circ} \mathrm{C}$

Respiratory rate, per min

Heart rates, beats/min

Systolic blood pressure,

$\mathrm{mmHg}$

Diastolic blood pressure,

$\mathrm{mmHg}$

Charlson Comorbidity Index

Oxford Acute Severity of

Illness Score

Cardiovascular comorbidities,

n (\%)

Ischemic heart disease

ACS

STEMI

NSTEMI

UA

SIHD

MI mechanical

complications

Hypertension

Myocardial disease

Valvar heart disease

Heart failure

NYHA functional classification

$$
\text { III-III }
$$$$
\text { IV }
$$

Cardiac shock

Cardiac arrest

Atrial arrhythmia

Ventricular arrhythmia

Bradycardia

Congenital heart disease

Pericardial disease

Aortic disease

Acute aortic syndrome

Cerebrovascular disease Acute stroke/TIA

Peripheral arterial disease

Venous thromboembolism

Noncardiovascular

comorbidities, n (\%)

Tobacco abuse

Alcohol abuse

Diabetes mellitus

Chronic kidney disease

Hypercholesterolemia
The 2-day avera
ICCU admission

$\begin{array}{cccc}\begin{array}{c}\leq 36 \mu \mathrm{g} / \mathrm{m}] \\ (\mathrm{N}=804)\end{array} & \begin{array}{c}37-63 \mu \mathrm{g} / \mathrm{m}[ \\ (\mathrm{N}=773)\end{array} & \begin{array}{c}\geq 64 \mu \mathrm{g} / \mathrm{m}] \\ (\mathrm{N}=760)\end{array} & \text { P value } \\ 65.9 \pm 14.0 & 64.9 \pm 14.6 & 65.8 \pm 13.9 & 0.316 \\ 473(58.8) & 434(56.1) & 446(58.7) & 0.938 \\ 558(69.4) & 531(68.7) & 500(65.8) & 0.128 \\ & & & \\ 503(62.6) & 536(69.3) & 565(74.3) & <0.001 \\ 254(31.6) & 201(26.0) & 165(21.7) & <0.001 \\ 47(5.8) & 36(4.7) & 30(3.9) & 0.080 \\ & & & \\ 176(21.9) & 164(21.2) & 178(23.4) & 0.474 \\ 424(52.7) & 367(47.5) & 292(38.4) & <0.001 \\ 204(25.4) & 242(31.3) & 290(38.2) & <0.001 \\ & & & \\ 36.4 \pm 0.8 & 36.4 \pm 0.7 & 36.2 \pm 2.7 & 0.208 \\ 20.4 \pm 3.5 & 20.3 \pm 3.1 & 20.2 \pm 4.5 & 0.745 \\ 79.3 \pm 21.5 & 79.8 \pm 20.5 & 80.6 \pm 22.4 & 0.467 \\ 125.7 \pm 45.0 & 124.0 \pm 42.5 & 125.5 \pm 45.8 & 0.717 \\ 72.6 \pm 15.8 & 72.7 \pm 15.8 & 72.6 \pm 17.4 & 0.988 \\ 2.3 \pm 1.8 & 2.3 \pm 1.9 & 2.4 \pm 1.9 & 0.198 \\ 21.5 \pm 9.8 & 22.4 \pm 10.7 & 23.7 \pm 10.7 & <0.001\end{array}$

578(71.9)

434(54.0)

214(26.6)

$114(14.2)$

106(13.2)

137(17.0)

$14(1.7)$

432(53.7)

$70(8.7)$

298(37.1)

472(58.7)

260(32.3)

$291(36.2)$

$167(20.8)$

$53(6.6)$

45(5.6)

$140(17.4)$

$63(7.8)$

$92(11.4)$

$13(1.6)$

$10(1.2)$

$6(0.7)$

$2(0.2)$

$75(9.3)$

$9(1.1)$

$18(2.2)$

$11(1.4)$

$279(34.7)$

$56(7.0)$

237(29.5)

$155(19.3)$

$118(14.7)$ concentration of $\mathrm{PM}_{2.5}$ before

$37-63 \mu \mathrm{g} / \mathrm{m} \square$

$64.9 \pm 14.6$

$434(56.1)$

$536(69.3)$

$201(26.0)$

$164(21.2)$

$367(47.5)$

242(31.3)

$36.4 \pm 0.7$

$20.3 \pm 3.1$

$79.8 \pm 20.5$

$22.4 \pm 10.7$

$587(75.9)$

468(60.5)

264(34.2)

123(15.9)

$81(10.5)$

$112(14.5)$

$10(1.3)$

391 (50.6)

65(8.4)

285(36.9)

458(59.2)

250(32.3)

266(34.4)

$179(23.2)$

64(8.3)

$52(6.7)$

$130(16.8)$

45(5.8)

90(11.6)

13(1.7)

9(1.2)

13(1.7)

$3(0.4)$

$55(7.1)$

$5(0.6)$

14(1.8)

$7(0.9)$

275(35.6)

$70(9.1)$

$210(27.2)$

$127(16.4)$

$122(15.8)$
469(61.7)

$270(35.5)$

$120(15.8)$

$79(10.4)$

75(9.9)

13(1.7)

388(51.1)

$64(8.4)$

268(35.3)

$460(60.5)$

266(35.0)

264(34.7)

$180(23.7)$

$59(7.8)$

$67(8.8)$

$142(18.7)$

$51(6.7)$

68(8.9)

$14(1.8)$

8(1.1)

14(1.8)

$6(0.8)$

78(10.3)

$12(1.6)$

18(2.4)

$11(1.4)$

245(32.2)

$57(7.5)$

212(27.9)

153(20.1)

139(18.3)
0.898

0.002

$<0.001$

0.371

0.080

$<0.001$

0.951

0.283

0.838

0.463

0.465

0.268

0.541

0.166

0.372

0.013

0.517

0.366

0.114

0.733

0.724

0.065

0.120

0.539

0.400

0.869

0.901

0.312

0.676

0.479

0.688

0.054 


\begin{tabular}{|c|c|c|c|c|}
\hline Chronic lung disease & $120(14.9)$ & $102(13.2)$ & $101(13.3)$ & 0.344 \\
\hline Malignancy & $30(3.7)$ & $25(3.2)$ & $23(3.0)$ & 0.436 \\
\hline Thyroid Disease & $17(2.1)$ & $8(1.0)$ & $20(2.6)$ & 0.479 \\
\hline Connective tissue disease & $7(0.9)$ & $9(1.2)$ & $10(1.3)$ & 0.400 \\
\hline Gout & $23(2.9)$ & $29(3.8)$ & $19(2.5)$ & 0.695 \\
\hline Moderate/severe anemia & $76(9.5)$ & $67(8.7)$ & $75(10.0)$ & 0.802 \\
\hline Hepatic dysfunction & $56(7.0)$ & $75(9.7)$ & $70(9.2)$ & 0.109 \\
\hline Dyskalemia & $216(26.9)$ & $232(30.0)$ & $228(30.0)$ & 0.168 \\
\hline Pneumonia/LRTI & $214(26.6)$ & $217(28.1)$ & $231(30.4)$ & 0.908 \\
\hline Major acute nonCV critical & $147(18.3)$ & $168(21.7)$ & $193(25.4)$ & 0.001 \\
\hline illnesses & & & & \\
\hline Acute respiratory failure & $95(11.8)$ & $114(14.7)$ & $133(17.5)$ & 0.00 \\
\hline Acute kidney injury & $96(11.9)$ & $107(13.8)$ & $118(15.5)$ & 0.039 \\
\hline Sepsis & $29(3.6)$ & $31(4.0)$ & $38(5.0)$ & 0.171 \\
\hline Gastrointestinal hemorrhage & $22(2.7)$ & $24(3.1)$ & $32(4.2)$ & 0.106 \\
\hline
\end{tabular}

Data are expressed as means \pm standard variation or counts and percentage, as appropriate.

Abbreviation: $\mathrm{PM}_{2.5}$, particulate matter with an aerodynamic diameter less than $2.5 \mu \mathrm{m}$; ACS, acute coronary syndrome; STEMI, ST-segment elevation myocardial infarction; NSTEMI, non-ST-segment elevation myocardial elevation; UA, unstable angina; SIHD, stable ischemic heart disease; MI, myocardial infarction; TIA, transient ischemic attack; CV, cardiovascular; LRTI, low respiratory tract infection.

Table 2. Major therapeutic characteristics of ICCU admission

\begin{tabular}{|c|c|c|c|c|}
\hline \multirow[b]{2}{*}{ Characteristic } & \multicolumn{3}{|c|}{$\begin{array}{l}\text { The 2-day average concentration of } \mathrm{PM}_{2.5} \text { before } \\
\text { ICCU admission }\end{array}$} & \multirow[b]{2}{*}{$P$ value } \\
\hline & $\begin{array}{c}\leq 36 \mu \mathrm{g} / \mathrm{m} \square \\
(\mathrm{N}=804)\end{array}$ & $\begin{array}{c}37-63 \mu \mathrm{g} / \mathrm{m} \square \\
(\mathrm{N}=773)\end{array}$ & $\begin{array}{c}\geq 64 \mu \mathrm{g} / \mathrm{m}] \\
(\mathrm{N}=760)\end{array}$ & \\
\hline $\begin{array}{l}\text { Percutaneous } \\
\text { intervention }\end{array}$ & $446(55.5)$ & $462(59.8)$ & $433(57.0)$ & 0.531 \\
\hline Temporary pacemaker & $78(9.7)$ & $72(9.3)$ & $60(7.9)$ & 0.214 \\
\hline Conventional pacemaker & $46(5.7)$ & $41(5.3)$ & $24(3.2)$ & 0.018 \\
\hline ICD & $7(0.9)$ & $4(0.5)$ & $4(0.5)$ & 0.389 \\
\hline CRT-P/D & $3(0.4)$ & $5(0.6)$ & $3(0.4)$ & 0.939 \\
\hline Ablation for tachycardia & $43(5.3)$ & $20(2.6)$ & $25(3.3)$ & 0.030 \\
\hline LAA closure & $16(2.0)$ & $2(0.3)$ & $13(1.7)$ & 0.593 \\
\hline TAVI or BAV & $18(2.2)$ & $10(1.3)$ & $23(3.0)$ & 0.302 \\
\hline $\begin{array}{l}\text { Interventional therapy for } \\
\text { CHD }\end{array}$ & $6(0.7)$ & $8(1.0)$ & $5(0.7)$ & 0.856 \\
\hline Intra-aortic balloon pump & $28(3.5)$ & $32(4.1)$ & $27(3.6)$ & 0.932 \\
\hline Inotropes or vasopressors & $90(11.2)$ & $115(14.9)$ & $107(14.1)$ & 0.089 \\
\hline Arterial line & $111(13.8)$ & $128(16.6)$ & $168(22.1)$ & $<0.001$ \\
\hline Central venous catheter & $66(8.2)$ & $74(9.6)$ & $87(11.4)$ & 0.031 \\
\hline Hemodialysis & $11(1.4)$ & $20(2.6)$ & $28(3.7)$ & 0.004 \\
\hline Mechanical ventilation & $87(10.8)$ & $104(13.5)$ & $125(16.4)$ & 0.001 \\
\hline
\end{tabular}

Data are expressed as counts and percentage.

Abbreviation: $\mathrm{PM}_{2.5}$, particulate matter with an aerodynamic diameter less than $2.5 \mu \mathrm{m}$; ICD, implantable cardioverter defibrillator; CRT-P/D, cardiac resynchronization therapy and pacemaker or defibrillator; LAA closure, left atrial appendage closure; TAVI, transcatheter aortic implantation; BAV, balloon aortic valvuloplasty; CHD, congenital heart disease. 


\begin{tabular}{|c|c|c|c|c|}
\hline \multirow[b]{2}{*}{ Outcomes } & $\begin{array}{l}\text { The 2-day ave } \\
\text { admission }\end{array}$ & oncentration & before ICCL & \multirow[b]{2}{*}{$P$ value } \\
\hline & $\begin{array}{c}\leq 36 \mu \mathrm{g} / \mathrm{m} \square \\
(\mathrm{N}=804)\end{array}$ & $\begin{array}{c}37-63 \mu \mathrm{g} / \mathrm{m} \square \\
(\mathrm{N}=773)\end{array}$ & $\begin{array}{l}\geq 64 \mu \mathrm{g} / \mathrm{m}] \\
(\mathrm{N}=760)\end{array}$ & \\
\hline $\begin{array}{l}\text { Primary endpoint } \\
\text { DAMA from hospital in } \\
\text { ECC }\end{array}$ & $\begin{array}{l}42(5.2) \\
20(2.5)\end{array}$ & $\begin{array}{l}56(7.2) \\
24(3.1)\end{array}$ & $\begin{array}{l}79(10.4) \\
39(5.1)\end{array}$ & $\begin{array}{l}<0.001 \\
0.005\end{array}$ \\
\hline DAMA from ICCU in & $15(1.9)$ & $20(2.6)$ & $32(4.2)$ & 0.006 \\
\hline $\begin{array}{l}\text { All-cause Death in } \\
\text { hospital }\end{array}$ & $22(2.7)$ & $32(4.1)$ & $40(5.3)$ & 0.011 \\
\hline ICCU All-cause death in & $21(2.6)$ & $30(3.9)$ & $33(4.3)$ & 0.065 \\
\hline
\end{tabular}

Data are expressed as median (interquartile) or counts (percentage), as appropriate.

Abbreviation: $\mathrm{PM}_{2.5}$, particulate matter with an aerodynamic diameter less than $2.5 \mu \mathrm{m}$; DAMA, discharge against medical advice; ECC, extremely critical condition, define as the composite of circulatory shock, electrical instability requiring emergency interventions, or acute respiratory failure with the need for mechanical ventilation.

\section{Figures}

A

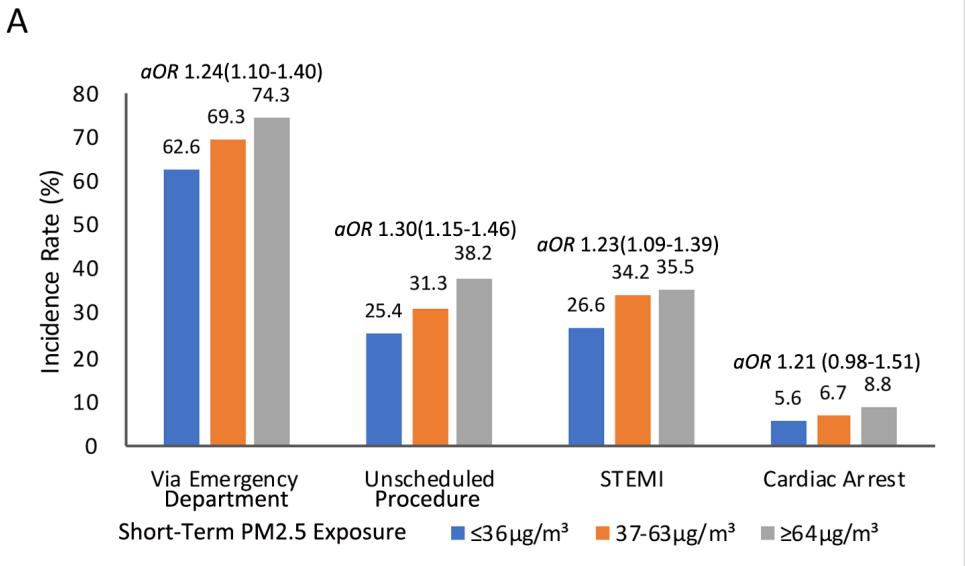

C

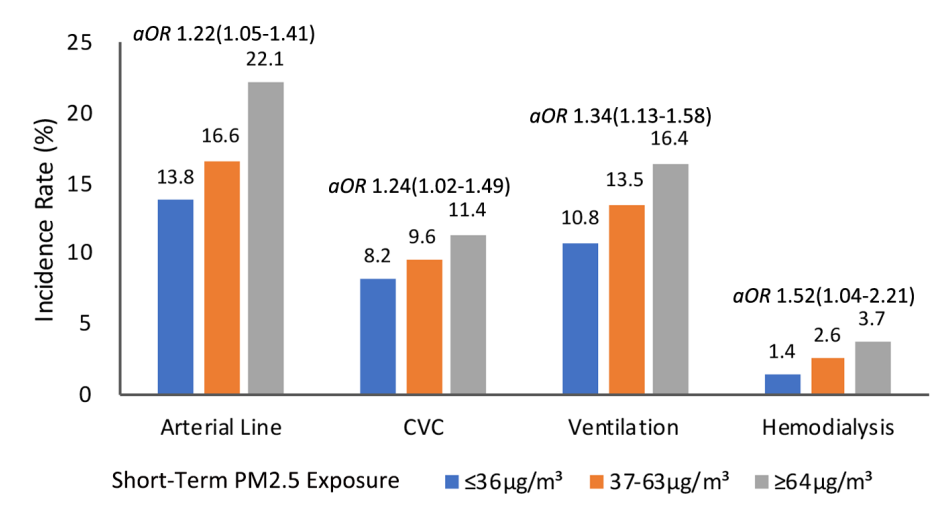

B

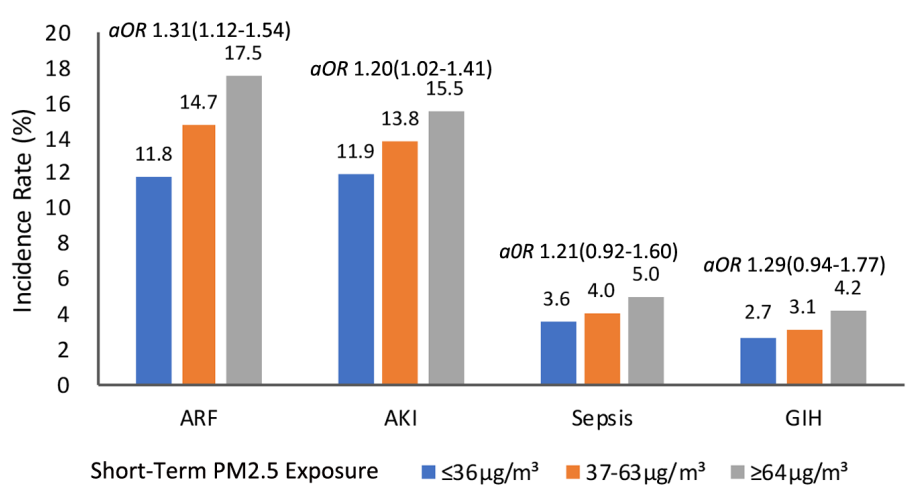

D

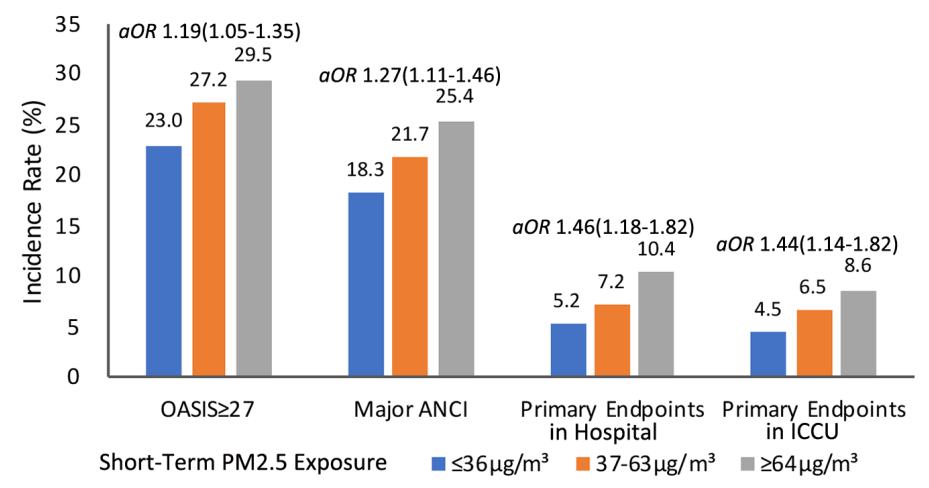


Adjusted odds ratios for important characteristics according to short-term PM2.5 exposure levels before ICCU admissions Adjusted odds ratios (aORs) were estimated by logistic regression models, controlling for mean temperature (per $5^{\circ} \mathrm{C}$ increase) and relative humidity (per 10\% increase). Short-term PM2.5 exposure, the 2-day average PM2.5 concentration before ICCU admission. PM2.5, particulate matter with an aerodynamic diameter less than $2.5 \mu \mathrm{m}$; STEMI, ST-segment elevation myocardial infarction; ARF, acute respiratory failure; $\mathrm{AKI}$, acute kidney injury; $\mathrm{GIH}$, gastrointestinal hemorrhage; $\mathrm{CVC}$, central venous catheter; OASIS, Oxford Acute Severity of IIIness Score; ANCI, major acute noncardiovascular critical illness, defined as the composite of acute respiratory failure, acute kidney injury, sepsis, or gastrointestinal hemorrhage; Primary endpoint, the composite of all-cause death or discharge against medical advice in extremely critical condition.

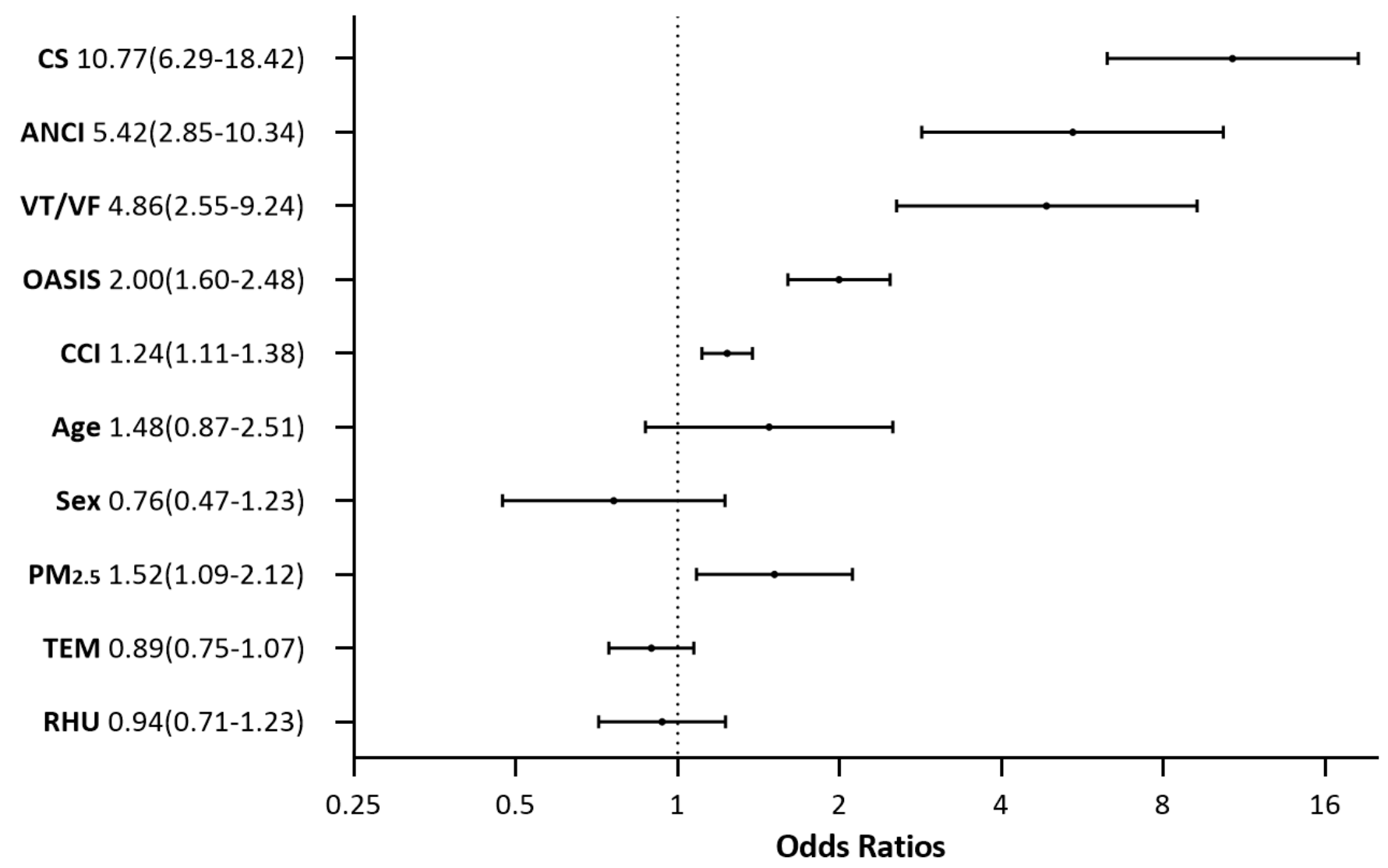

\section{Figure 2}

Predictor of in-hospital outcomes in ICCU patients Odds ratios (ORs) for the primary endpoint were estimated by multivariate logistic regression model. CS, cardiogenic shock; ANCl, major acute noncardiovascular critical illness, defined as the composite of acute respiratory failure, acute kidney injury, sepsis, or gastrointestinal hemorrhage; VT/VF, ventricular tachycardia or fibrillation; OASIS, Oxford acute severity of illnesses Score, entering the model with per 10 scores increase; CCl, Charlson Comorbidity Index; Age, greater than or equal to 65 years; PM2.5, particulate matter with an aerodynamic diameter less than $2.5 \mu \mathrm{m}$, entering the model with per tertile increase of the 2-day average concentration 
before ICCU admission; TEM, mean temperature, entering the model with per $5^{\circ} \mathrm{C}$ increase; RHU, relative humidity, entering the model with per $10 \%$ increase. 